\title{
Translators' Note
}

This translation of $O . O$. Gruzenberg's memoirs comprises all of Vchera: vospominaniia [Yesterday: Memoirs] (Paris, 1938), except for the several biographical sketches of professional acquaintances that Gruzenberg appended to the main text. The chapters have been slightly rearranged in order to provide a more chronological sequence. The chapter on the Soviet of Workers' Deputies is taken from O.O. Gruzenberg, Ocherki $i$ rechi [Essays and Speeches] (New York, I944), which was published by a group of Gruzenberg's friends after his death.

The transliteration of names generally follows the usage recommended in J. Thomas Shaw, The Transliteration of Modern Russian for English-Language Publications (Madison, 1967). Thus, System $I$ is used for names appearing in the text: $\ddot{e}=$ yo, $\ddot{k}=y$, $\mathfrak{r}=\mathrm{yu}, \mathrm{s}=\mathrm{ya}, \mathrm{rc}=\mathrm{x},-\mathrm{bh}=-\mathrm{y},-\mathrm{uh}=-\mathrm{y},-\mathrm{u} \Re=-\mathrm{ia}$; and System II for names appearing in bibliographical references:

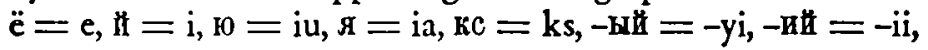
- ия $=-$ iia. Personal names having a non-Russian origin are rendered according to the nationality to which they belong. Thus, for example, Witte, Herzenstein, Lucis, and Spasowicz, rather than Vitte, Gertsenshtein, Lyuts, and Spasovich. Place names in non-Russian territory within the Empire, such as the Baltic provinces, are given according to their official Russian designation in the early twentieth century; but the first time they appear in the text, they are followed by their local usage. Thus, for example, Vilna [Vilnius], Verzhbolovo [Virbalis], and Libava [Liepaja].

Since Gruzenberg's writing reflects the distinctive oratorical style he used as a courtroom lawyer, some passages in his memoirs lack the necessary phrasing to convey the transitions of mood and ideas 
that he would have provided in vocal discourse by voice inflections, pauses, and changes of pace. Generally, we have tried to preserve in translation the structural characteristics of his writing; occasionally, we have inserted minor connective words and phrases for the sake of clarity and readability.

Gruzenberg's footnotes are preserved as he wrote them, and are indicated by asterisks; editorial comments and elaboration are presented in brackets and separate editorial footnotes are numbered to distinguish them from the author's.

D.C.R.

T.T. 